\title{
AFLPs congruent with morphological differentiation of Asian common minnow Zacco (Pisces: Cyprinidae) in Taiwan
}

\author{
Gwo-Chin Ma, Hsien-Shao Tsao, Hsiao-Pei Lu \& Hon-Tsen Yu
}

Accepted: 15 March 2006

doi:10.1111/j.1463-6409.2006.00232.x

\begin{abstract}
Ma, G.-C., Tsao, H.-S., Lu, H.-P. \& Yu, H.-T. (2006). AFLPs congruent with morphological differentiation of Asian common minnow Zacco (Pisces: Cyprinidae) in Taiwan. — Zoologica Scripta, 35, 341-351.

Morphological and amplified fragment length polymorphism (AFLP) analyses were used to examine the evolutionary relationships among Asian common minnows (Zacco spp.) in Taiwan, where four morphotypes were recently reported. Congruent results from the two sets of analyses indicate that the four morphotypes represent four separate morphometric clades with distinct AFLPs. Consequently, we conclude that four species exist in Taiwan and the systematics of Zacco should be revised accordingly. We also discuss conservation implications and offer a key to the four proposed Zacco species.

Gwo-Chin Ma, Institute of Zoology, National Taiwan University, Taipei, Taiwan 106, ROC. E-mail: d90225004@ntu.edu.tw

Hsien-Shao Tsao, Taipei Zoo, Taipei, Taiwan 116, ROC. E-mail: dwx07@zoo.gov.tw

Hsiao-Pei Lu, Institute of Zoology, National Taiwan University, Taipei, Taiwan 106, ROC. E-mail: r93b41003@ntu.edu.tw

Hon-Tsen Yu, Institute of Zoology and Department of Life Science, National Taiwan University, Taipei, Taiwan 106, ROC. E-mail: ayu@ntu.edu.tw
\end{abstract}

\section{Introduction}

The Asian common minnow Zacco is a cyprinid genus of small, colourful fishes that are dominant in the freshwater ecosystems of East Asia, which includes Japan, Korea, China and Taiwan (Bănărescu 1968; Chen 1998). However, since these minnows are morphologically diverse, the species boundaries and taxonomy are still inconclusive and misidentifications are not uncommon (Wang et al. 1997). Previous taxonomic studies have reported six Zacco species occurring in Taiwan (cf. Shen et al. 1993; Chen 1998): Zacco barbatus (Regan 1908), Zacco pachycephalus (Günther 1868), Zacco temminckii (Temminck \& Schlegel 1846), Zacco taiwanesis Chen 1982, Zacco evolans Jordan \& Evermann 1902 and Z. platypus (Temminck \& Schlegel 1846). However, the species originally described as Z. barbatus was reclassified into the genus Candidia (Jordan \& Richardson 1909), and this arrangement has been accepted by most taxonomists. Subsequently, Z. evolans was proposed as a synonym of $Z$. platypus (Oshima 1919), and the occurrence of Z. temminckii and Z. taiwanesis in Taiwan was considered to have resulted from the misidentification of Z. pachycephalus (Wang et al. 1997). Consequently, of the six nominal species, only Z. pachycephalus and Z. platypus are currently treated as valid species in Taiwan (Wang et al. 1997). Zacco pachycephalus, which is endemic to
Taiwan, occurs naturally in the western part of the country, and its range has been recently extended to eastern areas by artificial introductions of unknown origin (Wang et al. 1999). A previous allozyme study indicated that the species exhibits a great deal of genetic differentiation among populations, especially between samples from northern/middle and southern Taiwan (Wang et al. 1999). Zacco platypus, a common East Asian species, is found in Japan, Korea, China and Taiwan, but its range in Taiwan is restricted to the northern region. Genetic heterogeneities of Z. platypus among samples from Japan, Korea and Taiwan (Ming 1991) and among samples from different areas of China (Perdices et al. 2004; Berrebi et al.2005) have been reported. These results, taken together, imply the possibility that cryptic species exist in both Z. pachycephalus and Z. platypus.

Recently we discovered distinct morphotypes within currently recognized Taiwanese Z. pachycephalus and Z. platypus. We also noticed significant morphological differentiation between Chinese and Japanese samples of Z. platypus. Knowledge of the taxonomy and phylogenetic relationships of these Zacco is, however, incomplete. This is of importance because, at present, common minnows are the major target fish for anglers in Taiwan, at the same time that their population sizes have declined sharply due to environmental perturbations 
(cf. Chen 2001). Because of increasing pressure to conserve these species, defining evolutionary units in Zacco has become imperative and urgent. Morphological characters, both morphometric or meristic, have been commonly used to distinguish such units in fish (Dynes et al. 1999; Rincón 2000; Costa et al. 2003). Nevertheless, one interesting question to arise from this approach is whether or not morphological characters can be supported by genetic data that is currently deemed more pertinent in terms of the biological species concept (Mayr 1942). A notable feature of morphological characters is that certain features may not be directly under genetic control but, instead, induced by environmental factors. Such modifications are especially common in fish (e.g. Skúlason et al. 1989; Brönmark \& Miner 1992; Day et al. 1994). Moreover, comparisons based on such traits could erroneously lead to a conclusion of monophyly by clustering paraphyletic or polyphyletic groups. One way to overcome this difficulty is to simultaneously apply morphological and molecular genetic markers to the organisms of interest. Amplified fragment length polymorphisms (AFLPs; Vos et al. 1995) are good molecular markers for distinguishing species in these circumstances, not only because the technique is easy to use but also because it permits analysis on a suite of loci presumably spanning the whole genome without requiring prior sequence information (Ellis et al. 1997; Mueller \& Wolfenbarger 1999).

We performed a combined morphological and AFLP genetic investigation of the genus Zacco in Taiwan to estimate species divergence and to study the relationships among morphotypes. First, we describe patterns of differentiation in morphology, including meristic and morphometric characters, and investigate the genetic variation among morphologically distinct entities using AFLP. Second, the possible relevance of the underlying genetic and ecological factors that may be responsible for the morphological variability are discussed. Finally, we compare morphological and genetic differentiation and provide taxonomic resolution of Taiwanese Zacco, and we present a key to the proposed evolutionary units.

\section{Materials and methods Sampling}

A total of 175 Zacco (5.5-18.1 cm standard length) was collected from 15 major rivers in Taiwan (rivers $1-13, n=165$ ), Japan (river 14, $n=7$ ) and China (river 15, $n=3$ ) (Fig. 1 and Table 1). Sampling locations were selected to optimize spatial coverage within the distributional range of Zacco in Taiwan, including its native range (rivers 1-11) and artificially stocked areas (rivers 12 and 13). The sample included 93 Z. pachycephalus and 82 Z. platypus. These two currently recognized species have been reported as comprising more than one taxon each (Ming 1991; Wang et al. 1999; Perdices et al. 2004; Berrebi et al. 2005).

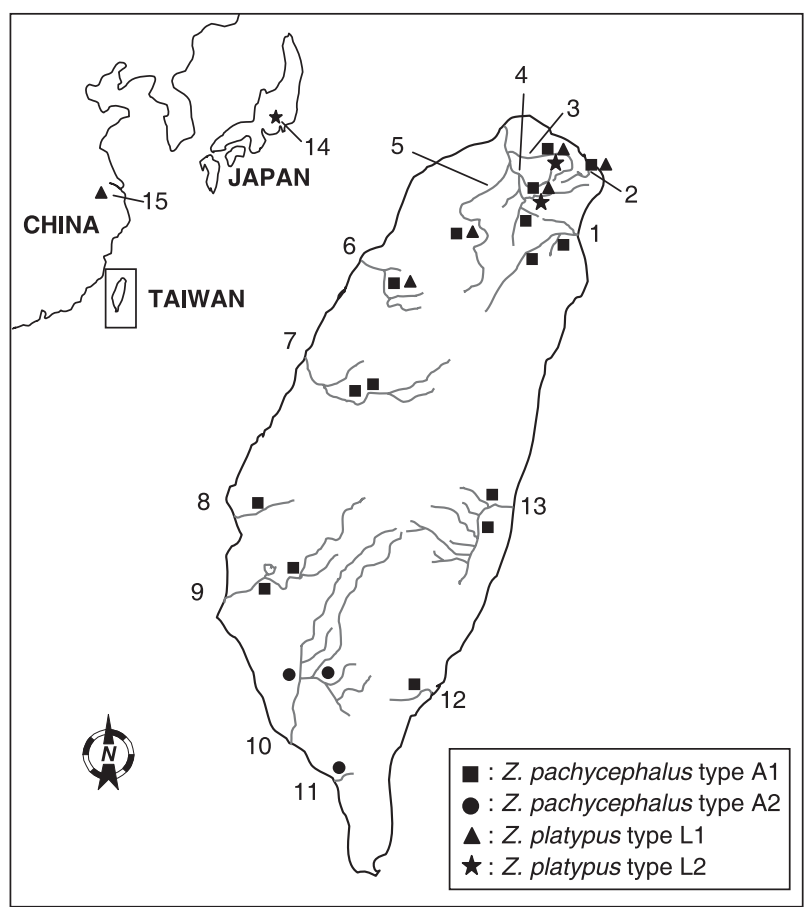

Fig. 1 Map showing sampling locations of the four Zacco morphotypes (i.e. type A1, A2, L1 and L2). - 1. Lanyang River; -2. Shuangshi River; -3. Keelung River; -4. Hsintien River; -5. Dahan River; -6. Houlung River; -7. Dadu River; -8. Putze River; -9. Tzenwen River; -10. Kaoping River; -11. Fangshan River; -12. Chipen River; - 13. Hsiukuluan River; - 14. Ara River (Japan); -15. Xinan River (China).

\section{Morphology}

Initially, individuals of $Z$. pachycephalus were divided into two morphotypes based on their geographic origins and head sizes: fish from northern, central and eastern Taiwan with a larger head/standard length (HL/SL) ratio of 0.22-0.32 (type A1), and fish restricted to southern Taiwan with a smaller HL/SL ratio of $0.20-0.25$ (type A2) (Fig. 2). In contrast, individuals of $Z$. platypus were divided into two morphotypes according to their nuptial colour patterns: blue discrete cross stripes (type L1) and bluish green irregular cross stripes (type L2) (Fig. 2). A peculiar breeding tubercle arrangement was also noted in type L2 males, in which 4-5 large breeding tubercles fused to form a ridge on male cheeks. This is in contrast to individual, round breeding tubercles found on type L1 male cheeks (Fig. 2).

Data on pigmentation, tubercle arrangement, eight meristic (Table 2) and 12 morphometric characters (Fig. 3) were recorded. Among meristic characters, pharyngeal teeth were dissected out and numbers of tooth rows were counted under a dissecting microscope. Numbers of fin rays and vertebrae were counted on double-stained specimens (Wassersug 1976) or X-ray images. For morphometric characters, measurements 
Table 1 Details on sample size of Zacco used for meristic, morphometric and AFLP analyses, by location and morphotype. Code numbers for sampling locations as indicated in Fig. 1.

\begin{tabular}{|c|c|c|c|c|}
\hline Morphotype & Location & $\begin{array}{l}\text { Sample size } \\
\text { meristic } \\
\text { counts }\end{array}$ & Morphometry & AFLP \\
\hline Zacco pachycephalus & & 48 & 66 & 39 \\
\hline \multirow{11}{*}{ type Al } & 1. Lanyang R. & 3 & 6 & 6 \\
\hline & 2. Shuangshi R. & 2 & 4 & 1 \\
\hline & 3. Keelung R. & 3 & 6 & 1 \\
\hline & 4. Hsintien R. & 10 & 10 & 9 \\
\hline & 5. Dahan R. & 6 & 7 & 4 \\
\hline & 6. Houlung R. & 5 & 7 & 7 \\
\hline & 7. Dadu R. & 5 & 5 & 2 \\
\hline & 8. Putze R. & 5 & 5 & 1 \\
\hline & 9. Tzenwen R. & 4 & 8 & 4 \\
\hline & 12. Chipen R. & 3 & 5 & 3 \\
\hline & 13. Hsiukuluan R. & 2 & 3 & 1 \\
\hline Zacco pachycephalus & & 17 & 27 & 24 \\
\hline \multirow[t]{2}{*}{ type A2 } & 10. Kaoping R. & 9 & 16 & 13 \\
\hline & 11. Fangshan R. & 8 & 11 & 11 \\
\hline Zacco platypus & & 24 & 33 & 30 \\
\hline \multirow[t]{6}{*}{ type L1 } & 2. Shuangshi R. & 4 & 6 & 6 \\
\hline & 3. Keelung R. & 2 & 2 & 2 \\
\hline & 4. Hsintien R. & 9 & 13 & 13 \\
\hline & 5. Dahan R. & 4 & 6 & 6 \\
\hline & 6. Houlung R. & 3 & 3 & 0 \\
\hline & 15. Xinan R. & 2 & 3 & 3 \\
\hline Zacco platypus & & 31 & 49 & 30 \\
\hline \multirow[t]{4}{*}{ type L2 } & 3. Keelung R. & 8 & 17 & 6 \\
\hline & 4. Hsintien R. & 19 & 25 & 17 \\
\hline & 14. Ara R. & 4 & 7 & 7 \\
\hline & Total & 120 & 175 & 123 \\
\hline
\end{tabular}

were taken from an image of each fish using a digitizer [Summagraphics, MMIII 1201 (Code Micro, CA, USA)], according to Garabana \& Saborido-Ray's procedure (http:// www.redfish.de/project/deliv02.pdf).

Differences between morphotypes for meristic characters were analysed using univariate statistics. As all meristic characters were independent of standard length (regressions were nonsignificant at $P<0.01$ ), no size adjustment of the data was performed. The nonparametric Kruskal-Wallis test was used to identify different meristic characters among morphotypes. Multiple comparisons were carried out using the Dunn procedure (Rosner 2000). All morphometric characters showed a linear relationship with standard length when analysed by specimen (all regressions were significant at $P<0.01$ ). Because growth allometry in morphometric characters results in a size effect when comparing fish of different sizes (Reist 1985; Rohlf \& Bookstein 1987), morphometric data were statistically adjusted to eliminate size-related variation, thus, permitting comparative analysis in terms of shape. First, morphometric measurements were transformed to common logarithms (i.e. base $=10$ ) in order to homogenize variance. It has been shown that the linearity and normality of morphometric data are usually more closely approached by log-transformed values than by original variables (Hair et al. 1998). Then, the common within-type regression coefficients between each log-transformed morphometric character and log-transformed standard length were estimated using analysis of covariance (ANCOVA). Regression coefficients were

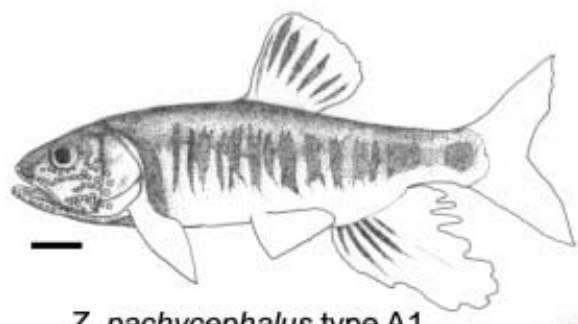

Z. pachycephalus type $\mathrm{A} 1$

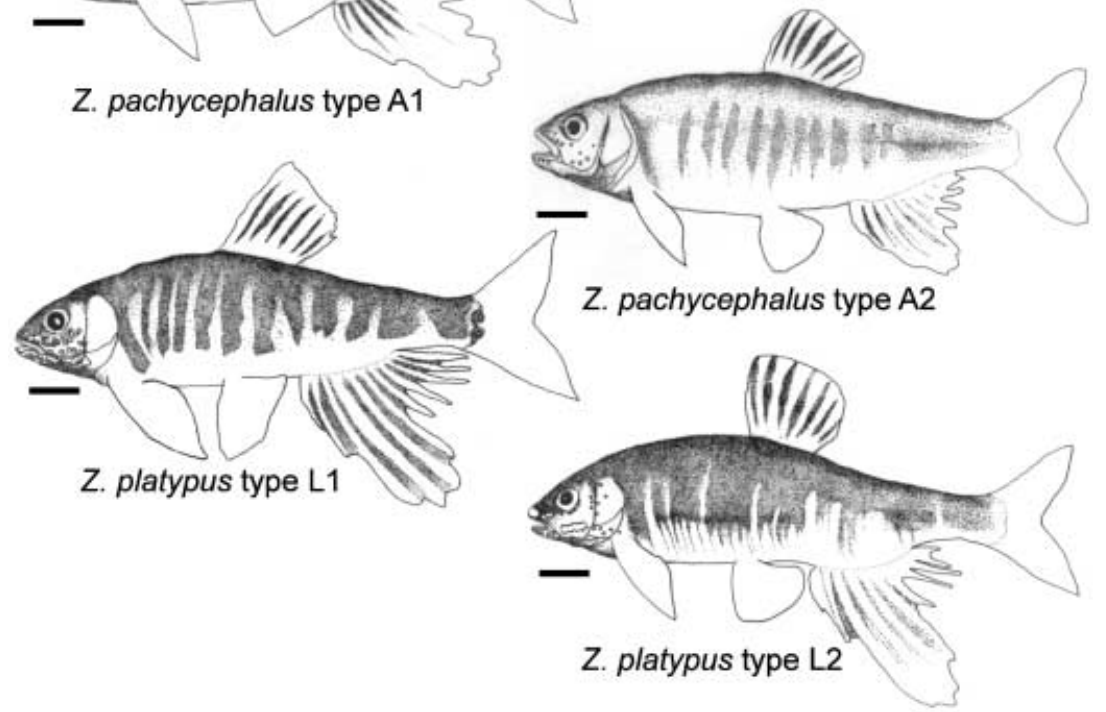

Fig. 2 Lateral view of the four Zacco morphotypes from Taiwan: A1 and A2 belong to Z. pachycephalus; L1 and L2 belong to Z. platypus. Adult males are shown. Scale bars, $10 \mathrm{~mm}$. 
Morphological and genetic analyses of Zacco • G.-C. Ma et al.

Table 2 Numerical counts and Kruskal-Wallis test for meristic characters of Zacco morphotypes A1, A2, L1 and L2. Values are modes (and ranges).

\begin{tabular}{|c|c|c|c|c|c|c|c|}
\hline \multirow[b]{2}{*}{ Character } & \multicolumn{2}{|c|}{ Z. pachycephalus } & \multicolumn{2}{|l|}{ Z. platypus } & \multicolumn{2}{|c|}{ Kruskal-Wallis test } & \multirow[b]{2}{*}{ Dunn test ${ }^{a}$} \\
\hline & Type A1 $(n=48)$ & Type A2 $(n=17)$ & Type L1 $(n=24)$ & Type L2 $(n=31)$ & H & $P$ & \\
\hline Dorsal fin rays* & iii, 7 & iii, 7 & iii, 7 & iii, 7 & 0.00 & 1.000 & - \\
\hline Pectoral fin rays* & i, 14 (i, 13-15) & i, 14 (i, 13-14) & i, 14 (i, 13-15) & i, 14 (i, 13-15) & 3.19 & 0.363 & - \\
\hline Pelvic fin rays* & $\mathrm{i}, 8(\mathrm{i}, 7-8)$ & $\mathrm{i}, 8(\mathrm{i}, 7-8)$ & $\mathrm{i}, 8(\mathrm{i}, 7-8)$ & $\mathrm{i}, 8$ (i, 7-8 & 0.42 & 0.936 & - \\
\hline Anal fin rays* & iii, 9 (iii, 8-9) & iii, 9 (iii, 8-9) & iii, 9 (iii, 8-9) & iii, 9 (iii, 8-10) & 2.49 & 0.477 & - \\
\hline Predorsal fin scales & $22(20-25)$ & $19(17-19)$ & $15(14-18)$ & $17(16-19)$ & 103.88 & $<0.000$ & $\mathrm{~A} 1 \mathrm{~A} 2 \mathrm{~L} 2 \mathrm{~L} 1$ \\
\hline Lateral line scales & $50(49-56)$ & $42(38-48)$ & $44(42-47)$ & $41(40-48)$ & 90.09 & $<0.000$ & $\mathrm{~A} 1 \overline{\overline{\mathrm{A} 2 \mathrm{L1}} \mathrm{L} 2}$ \\
\hline Vertebrae & $40(40-42)$ & $39(39-40)$ & $41(40-41)$ & $42(40-42)$ & 89.94 & $<0.000$ & $\underline{A 1}$ L1 A2 L2 \\
\hline Pharyngeal tooth rows & $3(2-3)$ & $3(2-3)$ & 3 & 3 & 8.31 & 0.040 & - \\
\hline
\end{tabular}

*Roman and Arabic alphabets indicate the numbers of unbranched and branched fin rays, respectively.

aunderlined morphotypes indicate no significant difference $(P>0.01)$.

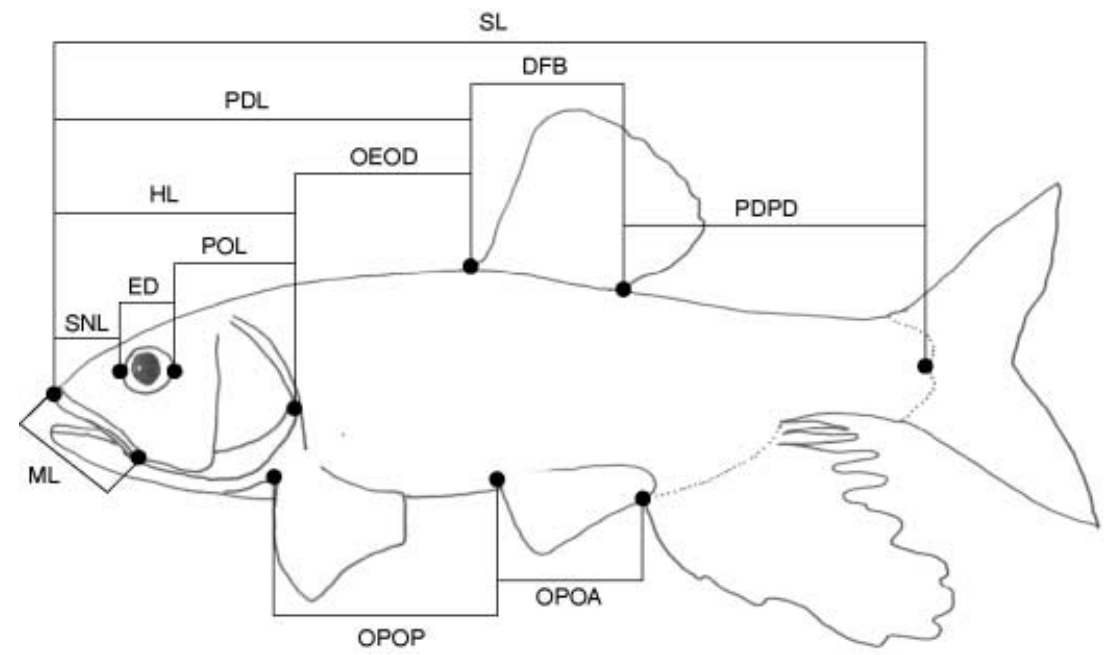

Fig. 3 Morphological characters used for morphometric analysis of Zacco. SL, standard length; PDL, predorsal fin length; DFB, dorsal fin base; HL, head length; OEOD, opercular edge to origin of dorsal fin; PDPD, posterior end of dorsal fin to end of caudal peduncle; SNL, snout length; ED, eye diameter; POL, postorbital length; ML, maxillary length; OPOP, origin of pectoral fin to origin of pelvic fin; OPOA, origin of pelvic fin to origin of anal fin. used for measurement adjustments according to an allometric formula: $\mathrm{AC}_{i}=\log \mathrm{OC}_{i}-\alpha\left(\log \mathrm{SL}_{i}-\log \mathrm{SL}_{\mathrm{M}}\right)($ Reist 1985; Rincón 2000; Costa et al. 2003), where $\mathrm{AC}_{i}$ is the adjusted logarithmic character measurement of the $i$ th fish; $\mathrm{OC}_{i}$ is the original character measurement of the $i$ th fish; $\alpha$ is the common within-type regression coefficient of the $\log \mathrm{C}-\log \mathrm{SL}$ relationship; $\mathrm{SL}_{i}$ is the standard length of the $i$ th fish; and $\mathrm{SL}_{\mathrm{M}}$ is the grand mean standard length. A multivariate principal component analysis (PCA) for the allometrically adjusted measurements was performed. The first two principal components (PC1 and PC2) were selected and scored. PC1 and PC2 were then regressed against standard length, and size effect was considered to be removed if regressions were not statistically significant. Difference between morphotypes for each allometrically adjusted measurement was also compared using univariate analysis of variance (ANOVA). Morphotype means were then multiply compared by Scheffe's test (Rosner 2000). The mathematical procedures were executed using the
SPSS statistical package (SPSS Inc. 1997). Unless otherwise indicated, statistical significance was determined at $P<0.01$.

\section{AFLP}

Genomic DNA was extracted from muscle tissue following standard phenol-chloroform procedures (Sambrook et al. 1989). AFLP analysis was performed according to Vos et al. (1995), with minor modifications. DNA digestion with $M s e \mathrm{I}$ and $E c o$ RI was carried out at $37^{\circ} \mathrm{C}$ for $3 \mathrm{~h}$. MseI and $E c o$ RI adaptors were subsequently ligated to digested DNA fragments with $200 \mathrm{U}$ T4 DNA ligase at $4{ }^{\circ} \mathrm{C}$ overnight to generate template DNA for amplification. Polymerase chain reaction (PCR) was performed in two successive reactions. Preamplification reactions used $M s e \mathrm{I}+\mathrm{A}$ and $E c o \mathrm{RI}+\mathrm{A}$ primers, each having one selective nucleotide. The pre-amplification products were then used as templates, after 10-fold dilution in sterile water, for fluorescent selective-amplification reactions using FAM-labelled MseI + ACG and fluorescence- 
Fig. 4 Plot of individuals on principal components 1 and 2 for Zacco types A1, A2, L1 and L2 based on adjusted morphometric characters. Fish collected outside Taiwan are marked solid ' $\boldsymbol{\Delta}$ ' and ' $\star$ ' for Chinese and Japanese samples, respectively.

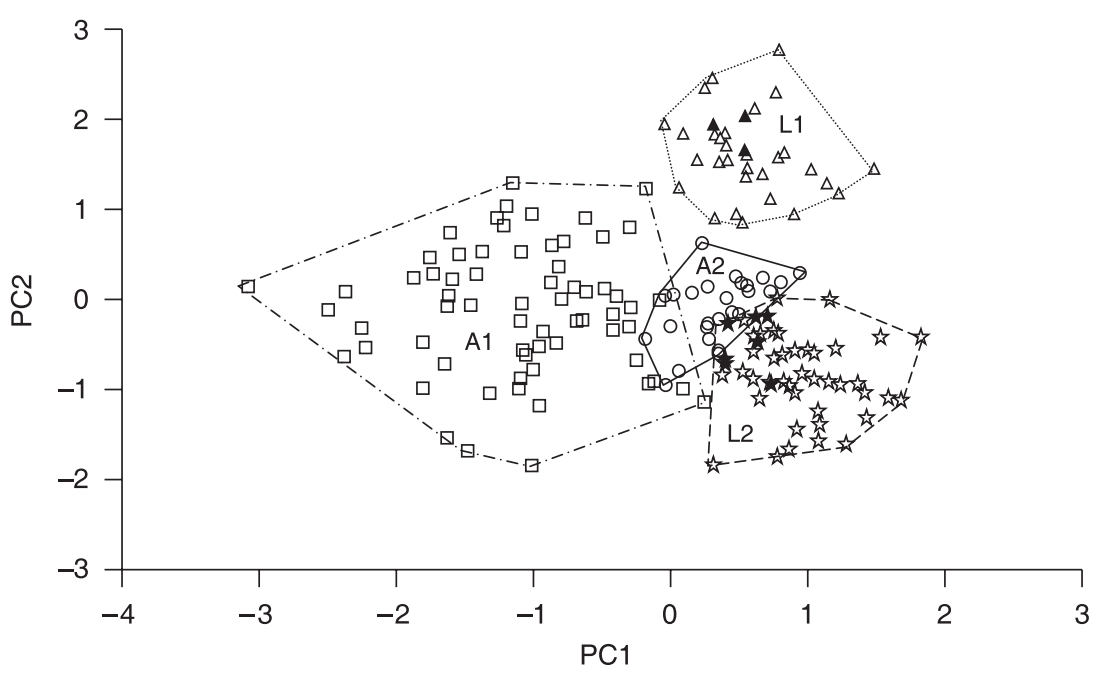

unlabelled EcoRI + ACT primers, each containing three selective nucleotides. Amplified DNA was analysed using a MegaBACE 1000 automated sequencer (Amersham Biosciences, PA, USA). A total of 194 AFLP markers, ranging from 46 to 239 base pairs, were scored by using Fragment Profiler 2.0 (Amersham Biosciences). Each AFLP marker was treated as present (1) or absent ( 0 ) to create a binary matrix. The matrix was used to estimate the pairwise genetic distance according to Nei \& Li (1979) $\{1-[2 a /(2 a+b+c)]\}$ and Jaccard (1908) $\{1-[a /(a+b+c)]\}$, where $a$ is the number of fragments shared by two individuals, and $b$ and $c$ are the numbers of fragments present in either of two individuals, respectively. The resulting distance matrices were used for neighbor-joining (NJ) analyses (Saitou \& Nei 1987). Genetic distance matrices were estimated using PhylTools (Buntjer 2000) and the NJ trees were drawn by MEGA 3 (Kumar et al. 2004). The reliability and robustness of the tree branch supports were tested by 500 bootstrap replications performed by PhylTools. Two specimens of Acrossocheilus paradoxus, which belonged to a different cyprinid subfamily (Barbinae) from the Zacco (subfamily: Rasborinae) were used as an outgroup. Calculations of genetic distances among Zacco groups, uncovered in NJ analyses, were then carried out with MEGA 3.

\section{Results}

\section{Morphology}

Significant differences (Kruskal-Wallis test, $P<0.01$ ) were found in three of the eight meristic characters among the four morphotypes (Table 2), i.e. numbers of predorsal fin scales, lateral line scales and vertebrae. Posterior comparisons among mean values showed that type A1 has significantly higher numbers of predorsal fin scales and lateral line scales than do the other three morphotypes (Dunn test, all $P<0.01$ ). Type L2 has significantly higher numbers of vertebrae and type A2 has significantly lower numbers of vertebrae when all morphotypes are considered (Dunn test, all $P<0.01$ ). Conversely, there was no significant difference in numbers of dorsal, pectoral, pelvic and anal fin rays and pharyngeal tooth rows among the four morphotypes (Kruskal-Wallis test, all $P>0.01)$.

Morphometrically, PCA supports distinction among the four Zacco morphotypes. Regressions for PC1 and PC2 against standard length were not significant (PC1: $F_{1,173}=12.2$, $P<0.000$; PC2: $\left.F_{1,173}=49.3, P<0.000\right)$, indicating that size effects had been removed from morphometric characters. Scatter plots of the first two principal components showed four separate groups, each representing a morphotype (Fig. 4). PC1 explained $65.30 \%$ of the total variation and type A1 was largely separated from the other types along this axis. In general, type A1 has a larger head and mouth than the other morphotypes as indicated by higher loadings for HL, SNL, POL and ML on PC1 (Table 3). However, the broad scatter of factor scores for type A1 in PCA plots (Fig. 4) indicated considerable variation within this morphotype. This is consistent with the empirical measurements for type A1; for example, HL varied from $21.7 \%$ to $31.7 \%$ of SL and ML varied from $9.0 \%$ to $15.1 \%$ of SL among individuals.

PC2 explained $10.72 \%$ of the overall variation among morphotypes, mainly reflecting differences in eye size (ED) and extended length of the operculum (POL) (Table 3). An interesting contrast in eye size appears between types $\mathrm{L} 1$ and L2 which are well separated on PC2, with L1 being 'largeeyed' and L2 being 'small-eyed' within the nominal species $Z$. platypus. Moreover, the results of the PCA suggest greater morphological differentiation between the two $Z$. platypus morphotypes (L1 and L2) than between the two Z. pachycephalus morphotypes (A1 and A2) (Fig. 4). ANOVA for morphometric characters further revealed significant differences in all 11 
Table 3 Character loadings and proportions of variance explained by first two principal components (PC1, PC2) for allometrically adjusted morphometric characters of Zacco. Abbreviations for morphometric characters as indicated in Fig. 3.

\begin{tabular}{lcr}
\hline Character & PC1 & \multicolumn{1}{c}{ PC2 } \\
\hline PDL & -0.0901 & -0.0238 \\
DFB & 0.0013 & 0.0956 \\
PDPD & 0.0993 & -0.0617 \\
HL & -0.3468 & -0.0096 \\
OEOD & 0.1577 & -0.1067 \\
SNL & -0.4612 & -0.1210 \\
ED & -0.0917 & 0.7050 \\
POL & -0.4463 & -0.5452 \\
ML & -0.6438 & 0.3246 \\
OPOP & 0.0393 & -0.0682 \\
OPOA & 0.0230 & -0.2368 \\
\% of variance & 65.30 & 10.72 \\
\hline
\end{tabular}

characters among the four types (all $P<0.000$, Table 4). Subsequent comparisons of mean values revealed significant differences between types A1 and A2 in six characters: HL, OEOD, SNL, POL, ML and OPOP (Scheffe's test, $P<0.01$ ), and significant differences between types L1 and L2 in seven characters: DFB, PDPD, OEOD, ED, POL, ML and OPOA (Scheffe's test, $P<0.01$ ).

\section{AFLP}

A total of 194 loci (fragment sizes 46-239 bp) was scored, of which $143(73.7 \%$ ) were polymorphic (at the 5\% level) in 123 Zacco (Table 1). Every fish examined was unique in terms of its AFLP haplotype, indicating a high degree of overall genetic diversity in Zacco. Thirty-one unique fragments were present in only one of the four Zacco morphotypes: 11 in type A1, three in type A2, eight in type L1 and nine in type L2. Genetic diversity in terms of percentage polymorphic loci (at the 5\% level) was lowest for type A2 (47.4\%), middle for type A1 (54.1\%) and type L1 (55.2\%), and highest for type L2 (60.3\%).

The NJ analysis based on Nei \& Li's (1979) distance generated a tree with three main Zacco clades (Fig. 5). Clade 1 included all fish of $Z$. pachycephalus (i.e. type A1 + A2), clade 2 consisted of $Z$. platypus type $L 1$ and clade 3 consisted of $Z$. platypus type L2. Within clade 1, two subclades corresponding to types A1 and A2 were identified (Fig. 5). Both subclades were highly supported with a bootstrap value of $75 \%$ for type A1 and $72 \%$ for type A2. In clade 2, two subclades with low bootstrap support (all < 50\%) were identified. Both subclades included fish from Taiwan but only one subclade included individuals from China (Fig. 5). In clades 3, two poorly supported subclades (all < 50\%) were also identified, but the two subclades are not geographically mutually exclusive, i.e. individuals from Taiwan and Japan are assigned to each (Fig. 5). The distance parameters used had limited influence on the composition of clades. The Jaccard's (1908) distance yielded a tree similar to that based on Nei \& Li's distance. Both distances were lowest for type A1 vs. A2 (Nei \& Li: 0.41, Jaccard 0.58) and highest for type A1 vs. L2 and type L1 vs. L2 (Nei \& Li: 0.64, Jaccard 0.78).

\section{Key to the morphotypes of Taiwanese Zacco}

1a. One orange spot on snout tip, body with bluish green irregular cross stripe (the stripe colour is light in females); 4-5 large breeding tubercles fused as a ridge on male cheeks (no breeding tubercles on female cheeks) Z. platypus type L2

1b. No spot on snout tip, body with $\geq 10$ blue discrete cross stripes (the stripe colour is light or obscure in females); separate, round breeding tubercles on male cheeks (no breeding tubercles on female cheeks) ..................... 2

2a. One vertical band of blue pigment on caudal peduncle end, body with moderate large scales; pectoral fin rather

Table 4 ANOVA test for $\log _{10}$-transformed and allometrically adjusted morphometric characters of Zacco morphotypes A1, A2, L1 and L2 . Values are mean (and standard error; SE). Abbreviations for morphometric characters as indicated in Fig. 3.

\begin{tabular}{|c|c|c|c|c|c|c|c|}
\hline \multirow[b]{2}{*}{ Character } & \multicolumn{2}{|l|}{ Z. pachycephalus } & \multicolumn{2}{|l|}{ Z. platypus } & \multicolumn{2}{|l|}{ ANOVA } & \multirow[b]{2}{*}{ Scheffe's test ${ }^{a}$} \\
\hline & Type A1 $(n=66)$ & Type A2 $(n=27)$ & Type L1 ( $n=33)$ & Type L2 $(n=49)$ & $F_{(3,171)}$ & $P$ & \\
\hline PDL & $1.654(0.0013)$ & $1.651(0.0021)$ & $1.630(0.0019)$ & $1.630(0.0015)$ & 71.5 & $<0.000$ & $\underline{\mathrm{A} 1 \mathrm{~A} 2} \mathrm{~L}$ 1 L2 \\
\hline DFB & $1.027(0.0047)$ & $1.044(0.0073)$ & $1.041(0.0066)$ & $1.011(0.0054)$ & 5.9 & $<0.000$ & $\underline{A} 2 \mathrm{~L} 1 \overline{\mathrm{A} 1} \mathrm{~L} 2$ \\
\hline PDPD & $1.550(0.0014)$ & $1.548(0.0022)$ & $1.567(0.0020)$ & $1.586(0.0016)$ & 108.7 & $<0.000$ & $\underline{\mathrm{A} 1 \mathrm{~A} 2} \overline{\mathrm{L} 1 \mathrm{~L} 2}$ \\
\hline $\mathrm{HL}$ & $1.385(0.0033)$ & $1.319(0.0052)$ & $1.306(0.0047)$ & $1.294(0.0039)$ & 126.6 & $<0.000$ & $\underline{\mathrm{A} 2 \mathrm{~L} 1}$ L2 A1 \\
\hline OEOD & $1.319(0.0026)$ & $1.374(0.0041)$ & $1.341(0.0037)$ & $1.362(0.0030)$ & 60.3 & $<0.000$ & $\underline{\mathrm{A} 2 \overline{\mathrm{L} 2 \mathrm{~A} 1} \mathrm{~L} 1}$ \\
\hline SNL & $0.822(0.0064)$ & $0.762(0.0100)$ & $0.727(0.0091)$ & $0.719(0.0074)$ & 44.6 & $<0.000$ & A2 L1 L2 A1 \\
\hline $\mathrm{ED}$ & $0.749(0.0038)$ & $0.730(0.0060)$ & $0.799(0.0054)$ & $0.703(0.0044)$ & 66.0 & $<0.000$ & 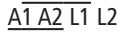 \\
\hline POL & $1.078(0.0043)$ & $0.981(0.0068)$ & $0.925(0.0061)$ & $0.977(0.0050)$ & 167.7 & $<0.000$ & $\underline{\mathrm{A} 2 \mathrm{~L} 2} \mathrm{~A} 1 \mathrm{~L} 1$ \\
\hline $\mathrm{ML}$ & $1.019(0.0053)$ & $0.884(0.0083)$ & $0.895(0.0075)$ & $0.827(0.0061)$ & 202.5 & $<0.000$ & 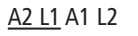 \\
\hline OPOP & $1.363(0.0034)$ & $1.387(0.0054)$ & $1.362(0.0048)$ & $1.375(0.0040)$ & 6.2 & $<0.000$ & $\underline{\mathrm{A} 2 \mathrm{~L} 2}$ L1 A1 \\
\hline OPOA & $1.232(0.0038)$ & $1.223(0.0059)$ & $1.212(0.0054)$ & $1.243(0.0044)$ & 7.4 & $<0.000$ & $\underline{\mathrm{L} 1 \overline{\mathrm{A} 1 \mathrm{~A} 2 \mathrm{~L} 2}}$ \\
\hline
\end{tabular}

a Underlined morphotypes indicate no significant difference $(P>0.01)$. 


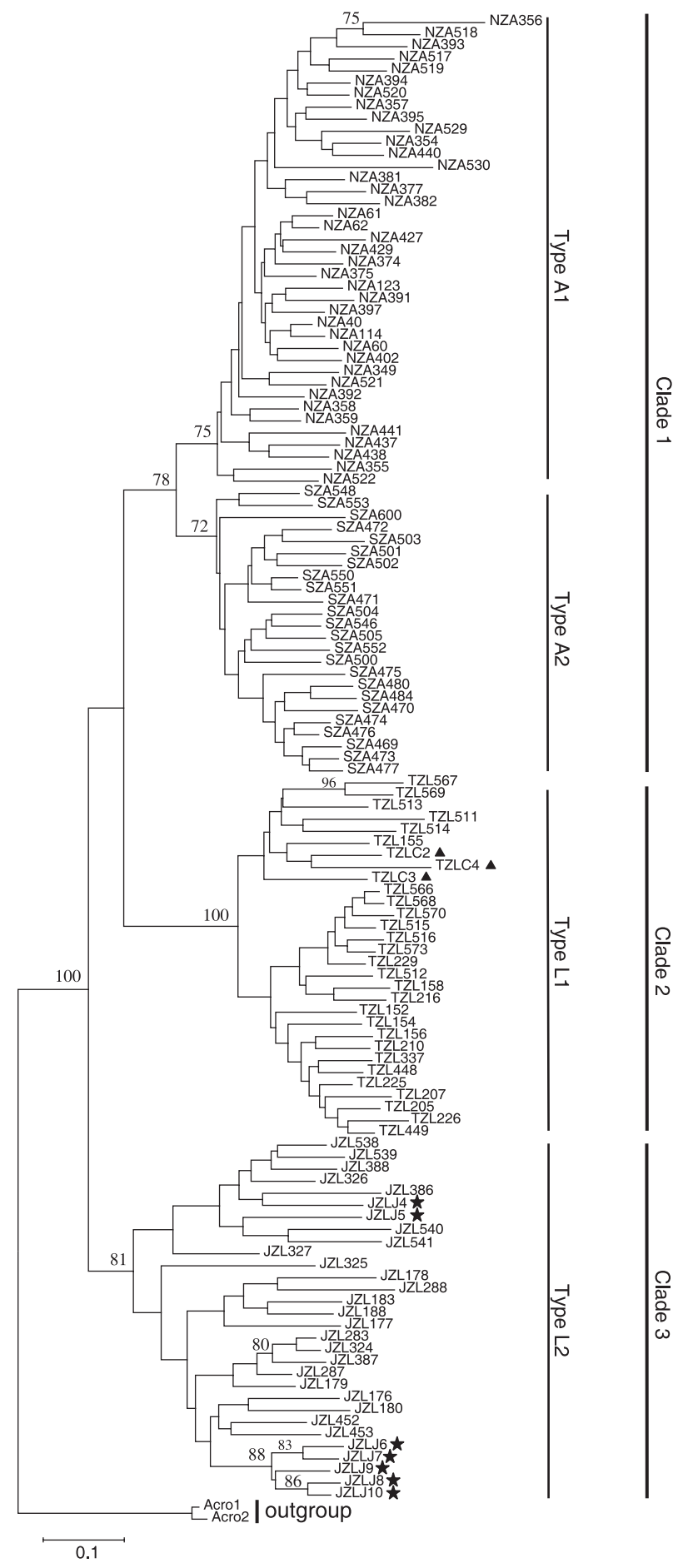

Fig. 5 Neighbor-joining tree of 123 individuals of the Zacco morphotypes A1, A2, L1 and L2 based on AFLPs. Genetic relationships were derived from Nei and Li's distance (1979). Numbers at tree nodes indicate bootstrap values $>70 \%$. Fish collected outside Taiwan are marked ' $\mathbf{\Delta}$ ' and ' $\star$ ' for Chinese and Japanese samples, respectively. long and tip extending to or beyond the pelvic fin origin in males Z. platypus type L1

2b. No band of pigment on caudal peduncle end, body with small scales, pectoral fin tip not extending to the pelvic fin origin .

3a. Twenty to 25 predorsal fin scales, 49-56 lateral line scales, maxillary length generally longer (9.0-15.1\% of the standard length), head size generally larger (21.7-31.7\% of the standard length); anal fin tip extending to or beyond the caudal peduncle end in breeding males. Z. pachycephalus type A1

3b. Seventeen to 19 predorsal fin scales, 38-48 lateral line scales, maxillary length generally shorter (7.7-9.5\% of the standard length), head size generally smaller (19.8-24.7\% of the standard length); anal fin tip not extending to the caudal peduncle end in breeding males. Z. pachycephalus type A2

\section{Discussion}

Our results indicate that the four Zacco morphotypes (A1, A2, L1 and L2) found in Taiwan are distinct in morphological and genetic characters and should be treated as separate evolutionary units. In contrast, populations within these morphotypes were remarkably similar in terms of their divergence in morphological characters across morphotypes, except for the type A1 which showed considerable variation in some morphological characters.

\section{Genetic basis of morphological variation}

Two lines of evidence indicate that genetic differentiation is in accordance with morphological differentiation among the four morphotypes. First, all individuals examined belonged to one morphotypes were clustered into the same AFLP clade with a high bootstrap support. Second, similar forms of morphological variation were found at multiple locations, even among sympatric individuals in northern Taiwan (types A1, L1 and L2) and those of south-western Taiwan (types A1 and A2). If morphotype-specific morphologies are largely the result of environmental factors, similar environmental conditions between relatively close areas would effectively reduce the magnitude of variation. As stated above, both distinctions in morphology and congruence of morphological and genetic data suggest that barriers to gene flow act to maintain the observed morphologies. The gene flow could be reduced by intrinsic mechanisms, such as hybrid incompatibility or hybrid breakdown, or external factors, such as restricted dispersal (see below).

The notable morphological variation in type A1 fish has frequently resulted in their misidentification (cf. Wang et al. 1997), although the AFLP data show similar patterns of genomic profiling among individuals (Fig. 5). One explanation of the relatively higher morphological diversity among individuals of this morphotype is that A1 contains higher 
genetic variability that is reflected in its morphology. Alternatively, environmental conditions resulting in phenotypic plasticity or the interactions between genetic and environmental factors could cause the high degree of morphological variation observed, as reported in many other fish species (Skúlason et al. 1989; Brönmark \& Miner 1992; Day et al. 1994). A high degree of morphological flexibility, in turn, has the advantage of permitting rapid adaptation in different environmental conditions. This may account for the wide distribution of type A1 fish in various freshwater ecosystems (e.g. streams, rivers, pools, reservoirs).

\section{Evolutionary aspect of morphological divergences}

The NJ analysis based on AFLP data among the four morphotypes confirmed the close relationship between the two Z. pachycephalus morphotypes, A1 and A2 (Fig. 5). This relationship is strongly supported by high bootstrap replications and is concordant with previous allozyme results (Wang et al. 1999). The close relationship and allopatric distribution pattern of these two morphotypes (Fig. 1) suggest that they are vicariant lineages isolated by historical biogeographic barriers near south-western Taiwan. Wang et al. (1999), based on allozymes and geological evidence, proposed that an extremely steep sea trench near the Kaoping estuary may act as a significant historical barrier to speciation (c. 10000 6000 years ago), by which $Z$. pachycephalus as well as other freshwater species of fish in Taiwan are currently divided into northern/middle and southern groups. According to this hypothesis, the differentiation (both morphological and genetic) between types A1 and A2 is likely the result of prolonged isolation during this period. We found significant differentiation in head morphology (HL, SNL and POL) and maxillary length (ML) between types A1 and A2 in line with their geographical separation. Type A1 from northern and middle Taiwan is, on average, larger and more robust in these morphological characters than type A2 from southern Taiwan. Head morphology is of considerable importance for feeding and differentiation in the shape of the maxillary often reflects changes in forging mode or diet composition (Skúlason et al. 1989; Langerhans et al. 2003). In the wild, Zacco feed on algae, aquatic insects and other invertebrates. Differences in climatic patterns and hydrological conditions between northern and southern Taiwan (Lin \& Chou 1974) could influence the community structures of aquatic biota and, thereby, cause varying selection pressures in the functional morphology of fish feeding. Consequently, the morphological differences between types $\mathrm{A} 1$ and $\mathrm{A} 2$ probably reflect their genetic differentiation as a consequence of prolonged isolation combined with differences in the natural environment and diet.

In contrast to the results obtained for types A1 and A2 of $Z$. pachycephalus, the $\mathrm{NJ}$ tree did not support a close relationship between the two Z. platypus morphotypes, L1 and L2
(Fig. 5). Type L1 did not group with type L2 but grouped instead with the clade of $Z$. pachycephalus (type A1 + type A2). Furthermore, pairwise comparisons indicated a relatively high genetic differentiation between types L1 and L2, with a Nei \& Li's distance of 0.64 and a Jaccord's distance of 0.78 . These two morphotypes were separated on the basis of prominent differences in their nuptial colour patterns and breeding tubercle arrangements (Fig. 2). Morphometric analysis further indicated that type L1 is 'large-eyed' and type L2 is 'small-eyed' within the nominal species $Z$. platypus (Fig. 4 and Table 4). Because types L1 and L2 are sympatric in northern Taiwan (Fig. 1), the magnitude of AFLP variation and morphological variation suggest that these two morphotypes are distinct species. Individuals of intermediate morphology were never observed, implying hybridization between these two morphotypes is extremely rare, if it exists at all, in the wild. Nuptial coloration and breeding tubercles are reproductive characters for many fish and it has been suggested that patterns of these characters are important in species recognition and mate choice (Winfield \& Nelson 1991; Skarstein \& Folstad 1996; Kortet et al. 2004). In both types L1 and L2, the degree of nuptial coloration and extent of tubercle ornamentation are particularly conspicuous in sexually active males, although coloration and tubercle are often unapparent in females and subadults. This implies that nuptial colour patterns and breeding tubercle arrangements may play roles in Zacco morphotype recognition and possibly act as reproductive barriers between morphotypes. Even though in situ disruptive sexual selection in nuptial colour patterns has been proposed as a common mode of speciation among cichlids (Knight et al. 1998; Seehausen et al. 1998), it seems highly improbable that the divergence of types L1 and L2 was initiated in such a way in northern Taiwan because these two morphotypes are not monophyletic in origin, and are not sister taxa to each other (Fig. 5). Supposing that disruptive selection does facilitate speciation between types L1 and L2 by acting as the initial step in divergence, it would then be expected that these two morphotypes are genetically closely related, and therefore recently diverged. Our Chinese samples of the nominal Z. platypus belong to type L1 whereas Japanese samples of nominal Z. platypus are type L2. Therefore, the sympatry of type L1 and type L2 in northern Taiwan is of particular interest because outside Taiwan type L1 and type L2 are allopatric (type L1 occurs in China and type L2 occurs in Japan and Korea). Such distributions suggest that the sympatry of type L1 and type L2 in northern Taiwan might result from secondary contact. Therefore, the morphological differences between L1 and L2 could be a consequence of the long independent histories of these morphotypes. We did not detect any major habitat differences between types L1 and L2 in northern Taiwan so environment-mediated divergences might be minor. 


\section{Taxonomic and conservation implications}

The finding of four genetically distinct morphotypes (A1, A2, L1 and L2) in Taiwanese Zacco contrasts with Wang et al.'s (1997) taxonomic conclusion that there are only two valid Zacco species in Taiwan, Z. pachycephalus and Z. platypus. Furthermore, types L1 and type L2, which both currently belong to the nominal species $Z$. platypus, do not form a monophyletic group in the AFLP analysis. These results, and the fact that we did not find any hybrid individuals between types L1 and L2 in northern Taiwan, suggest that the current systematic scheme of Taiwanese Zacco needs revision.

Zacco pachycephalus is an endemic species of Taiwan. Günther (1868) described Z. pachycephalus according to fish from northern Taiwan (Taipei) and gave the characters: (1) 'The length of the head is contained from thrice and a half to thrice and three-fourths in the total length (without caudal)' and (2) 'mouth rather wide, the maxillary extending somewhat beyond the vertical from the front margin of the eye.' Applying these two diagnostic characters and the sampling locality, we find type A1 in agreement with the original description of $Z$. pachycephalus. Therefore, type A1 is recognized as $Z$. pachycephalus (Günther 1868).

Type A2 is not only morphologically distinct but also geographically separated from type A1. Furthermore, the reciprocally monophyletic relationship of the types A1 and A2 should merit a new species status for the type A2, other than the previously reported Z. temminckii (Oshima 1919) or Z. taiwanesis Chen 1982. Type A2 with $\geq 10$ blue discrete cross stripes on both sides of its body does not fit the description of Z. temminckii, which has a dark longitudinal band along the body. Although type A2 is similar to Z. taiwanesis in having such blue discrete cross stripes, it does not correspond to the reported distributional range of $Z$. taiwanesis ('Choshi River' in middle Taiwan, the range of type A1). Consequently, the type A2 might represent a new taxon which has not yet been described.

Zacco platypus had been long considered a single species across the whole of East Asia (Bănărescu 1968; Shen et al. 1993). Our results indicate that two Z. platypus morphotypes (types L1 and L2) are sympatric in northern Taiwan and should be treated as different species. Temminck \& Schlegel (1846) first described Z. platypus based on samples from Japan. The morphological characters designated for this species include a peculiarly striped colour pattern: body with a series of greenish, irregular cross bands (Temminck \& Schlegel 1846). Such a striped pattern is typical for 'Japanese Z. platypus' (see Nakabo 1993) and for type L2 rather than type L1. Furthermore, in our samples, all fish from Japan belong to type L2 morphologically and genetically. Consequently, we conclude that type L2 is Z. platypus as described by Temminck \& Schlegel (1846). Jordan \& Evermann (1902), based on morphological differentiation between Taiwanese and Japanese 'Z. platypus', named a new species Z. evolans for Taiwanese samples, but their nomenclature was not followed by other authors. Overall, Z. evolans is distinct from Z. platypus by having (1) a body with about 12 discrete cross bars and (2) a long pectoral fin the tip of which can reach the middle of the ventral fin (Temminck \& Schlegel 1846; Jordan \& Evermann 1902). This description is in line with the differences observed between types L1 and L2. The morphometric and meristic measurements of $Z$. evolans (Jordan \& Evermann 1902) are within the range of the intratype L1 variation. Furthermore, a figure of Z. evolans provided by Jordan \& Evermann (1902) resembles type L1, especially in having large eye size and in the stripe pattern. Therefore, we propose that $Z$. evolans may represent type L1. However, further studies, including more extensive collections from throughout Zacco's range as well as the type specimen examinations are needed because type $\mathrm{L} 1$ is also distributed in China where several nominal species for the so-called ' $Z$. platypus' have been reported (cf. Chen 1998).

In conclusion, the current cyprinid genus Zacco is a group exhibiting a great deal of morphological variation, which is reflected in its uncertain and often contradictory taxonomic treatments (cf. Oshima 1919; Bănărescu 1968; Shen et al. 1993; Ashiwa \& Hosoya 1998; Chen 1998). To address this issue, we have incorporated genetic information into morphological analyses to resolve the relationships among its congeners. The discontinuities observed in both morphological and genetic characteristics signify patterns and processes of speciation in Zacco. This is of importance for the taxonomy as well as the conservation of Taiwanese Zacco in order to ensure that the evolutionary lineages are recognized and their evolutionary potential conserved. Undoubtedly, the four morphotypes harbouring distinct morphological and genetic characters are separate evolutionary units and should be the focus of conservation efforts. Populations of these units should not be merged and they may require separate management strategies to maintain overall biodiversity. We also agree with Crandall et al. (2000) that consideration of ecology is equally important for species conservation, even when morphological and genetic data are available. Thus, comparative studies of life history and behavioural characteristics of these evolutionary units may reveal additional differences among taxa and provide additional information that will prove critical in developing management plans.

\section{Acknowledgements}

H.-D. Lin provided his Chinese fish specimens. I.-S. Chen assisted in collecting fish from Kaoping River. This research was supported by the Council of Agriculture and by a themeproject grant from Academia Sinica, Republic of China. We thank them all. 


\section{References}

Ashiwa, H. \& Hosoya, K. (1998). Osteology of Zacco pachycephalus, sensu Jordan \& Evermann (1903), with special reference to its systematic position. Environmental Biology of Fishes, 52, 163-171.

Bănărescu, P. (1968). Revision of the genera Zacco and Opsariichthys (Pisces, Cyprinidae). Vestník Československé Spolećnosti Zoologické, 32, 305-311.

Berrebi, P., Boissin, E., Fang, F. \& Cattaneo-Berrebi, G. (2005). Intron polymorphism (EPIC-PCR) reveals phylogeographic structure of Zacco platypus in China: a possible target for aquaculture development. Heredity, 94, 589-598.

Brönmark, C. \& Miner, J. G. (1992). Predator-induced phenotypical change in body morphology in crucian carp. Science, 258, 13481350 .

Buntjer, J. (2000). Phyltools-a tool for the processing and distance calculation for phylogenetic data sets. Available via http:// www.dpw.wau.nl/pv/PUB/pt/.

Chen, I. S. (2001). The history of investigation, geographical distribution and conservation of Taiwanese freshwater fishes. Taiwan Documents, 52, 45-60.

Chen, Y. Y. (1982). Revision of the fishes of genera Opsariichthys, Zacco, Candidia and Parazacco. Oceanic Linnology, 13, 293-298.

Chen, Y. Y. (1998). Fauna Sinica. Ostichthyes Cypriniformes II. Beijing, China: Science Press.

Costa, J. L., Almeida, P. R. D. \& Costa, M. J. (2003). A morphometric and meristic investigation of Lusitanian toadfish Halobatrachus didactylus (Bloch and Schneider, 1801): evidence of population fragmentation on Portuguese coast. Scientia Marina, 67, 219-231.

Crandall, K. A., Bininda-Emonds, O. R. P., Mace, G. M. \& Wayne, R. K. (2000). Considering evolutionary processes in conservation biology. Trends in Ecology \& Evolution, 15, 90-295.

Day, T., Pritchard, J. \& Schluter, D. (1994). A comparison of two sticklebacks. Evolution, 48, 1723-1734.

Dynes, J., Magnan, P., Bernatchez, L. \& Rodríguez, M. A. (1999). Genetic and morphological variation between two forms of lacustrine brook charr. Fournal of Fish Biology, 54, 955-972.

Ellis, R. P., McNicol, J. W., Baird, E., Booth, A., Lawrence, P., Thomas, B. \& Powell, W. (1997). The use of AFLPs to examine genetic relatedness in barley. Molecular Breeding, 3, 359-369.

Günther, A. (1868). Catalogue of the Fishes in British Museum, Vol. 7. London: British Museum.

Hair, J. F. Jr, Amderson, R. E., Tatham, R. \& Black, W. C. (1998). Multivariate Data Analysis. Upper Saddle River, NJ: Prentice Hall.

Jaccard, P. (1908). Nouvelles recherches sur la distribution florale. Bulletin de la Société Vaudoise des Sciences Naturelles, 44, 223-270.

Jordan, D. S. \& Evermann, B. W. (1902). Notes on a collection of fishes from the Island of Formosa. Proceeding of the United States National Museum, 25, 322.

Jordan, D. S. \& Richardson, B. W. (1909). A catalogue of the fishes of Formosa, or Taiwan, based on the collection of Dr. Hans Sauter. Memoirs of the Carnegie Museum, 4, 170.

Knight, M. E., Turner, G. F., Rico, C., van Oppen, M. J. H. \& Hewitt, G. M. (1998). Microsatellite paternity analysis on captive Lake Malawi cichlids supports reproductive isolation by direct mate choice. Molecular Ecology, 7, 1605-1610.

Kortet, R., Vainikka, A., Rantala, M. J. \& Taskinen, J. (2004). Sperm quality, secondary sexual characters and parasitism in roach
(Rutilus rutitus L.). Biological Fournal of the Linnean Society, 81, 111-117.

Kumar, S., Tamura, K. \& Nei, M. (2004). MEGA 3: integrated software for molecular evolutionary genetics analysis and sequence alignment. Briefings in Bioinformatics, 5, 150-163.

Langerhans, R. B., Layman, C. A., Langerhans, A. K. \& Dewitt, T. J. (2003). Habitat-associated morphological divergence in two Neotropical fish species. Biological Fournal of the Linnean Society, 80, 689-698.

Lin, C. C. \& Chou, G. T. (1974). The Geology of Taiwan. Nantou, Taiwan: Taiwanese Literature Committee.

Mayr, E. (1942). Systematics and the Origin of Species. New York: Columbia University Press.

Ming, M. S. (1991). Systematic study on the genus Zacco (Pisces, Cyprinidae). PhD Thesis, Jen-Heh University, Korea.

Mueller, U. G. \& Wolfenbarger, L. L. (1999). AFLP genotyping and fingerprinting. Trends in Ecology \& Evolution, 14, 389-394.

Nakabo, T. (1993). Fishes of Japan with Pictorial Keys to the Species. Kanagawa, Japan: Tokai University Press.

Nei, M. \& Li, W.-H. (1979). Mathematical models for studying genetic variation in terms of restriction endonucleases. Proceedings of the National Academy of Sciences, USA, 76, 5269-5273.

Oshima, M. (1919). Contributions to the study of the fresh water fishes of the island of Formosa. Annals of Carnegie Museum, 12, 234-241.

Perdices, A., Cunha, C. \& Coelho, M. M. (2004). Phylogenetic structure of Zacco platypus (Teleostei, Cyprinidae) populations on the upper and middle Chang Jiang (Yangtze) drainage inferred from cytochromoe b sequences. Molecular Phylogenetics and Evolution, 31, 192-203.

Regan, C. T. (1908). Descriptions of new fishes from Lake Candidius Formosa, collected by Dr. A. Moltrecht. Annals and Magazine of Natural History, 8, 358-360.

Reist, J. D. (1985). An empirical evaluation of several univariate methods that adjust for size variation in morphometric variation. Canadian Fournal of Zoology, 63, 1429-1439.

Rincón, P. A. (2000). Big fish, small fish: still the same species. Lack of morphometric evidence of the existence of two sturgeon species in the Guadalquivir river. Marine Biology, 136, 715-723.

Rohlf, F. J. \& Bookstein, F. L. (1987). A common on shearing as a method for 'size correction'. Systematic Zoology, 36, 356-367.

Rosner, B. (2000). Fundamentals of Biostatistics. Belmont, California: Duxbury/Thomson Learning.

Saitou, N. \& Nei, M. (1987). The neighbor-joining method: a new method for reconstructing phylogenetic trees. Molecular Biology and Evolution, 4, 406-425.

Sambrook, J., Fritsch, E. F. \& Maniatis, T. (1989). Molecular Cloning: A Laboratory Manual. Cold Spring Harbor, New York: Cold Spring Harbor Laboratory Press.

Seehausen, O., Witte, F., van Alphen, J. J. M. \& Bouton, N. (1998). Direct mate choice maintains diversity among sympatric cichlids in Lake Victoria. Fournal of Fish Biology, 53, 37-55.

Shen, S. C., Lee, S. C., Shao, K. T., Mok, H. K., Chen, C. F. \& Chen, C. T. (1993). Fishes of Taiwan. Taipei: National Taiwan University.

Skarstein, F. \& Folstad, I. (1996). Sexual dichromatism and the immunocompetence handicap: an observational approach using arctic charr. Oikos, 76, 359-367.

Skúlason, S., Noakes, D. L. G. \& Snorrason, S. S. (1989). Ontogeny 
of trophic morphology in four sympatric morphs of arctic charr Salvelinus alpinus in Thingvalavatn, Iceland. Biological fournal of the Linnean Society, 38, 281-301.

SPSS Inc. (1997). SPSS Base 7.5 Applications Guide. Chicago, IL: SPSS.

Temminck, G. J. \& Schlegel, H. (1846). Pisces in Siebold's Fauna faponica. Leiden: Lugduni Batavorum.

Vos, P., Hogers, R., Bleeker, M., Reijans, M., Lee, T., van de Hornes, M., Frijters, A., Pot, J., Peleman, J., Kuiper, M. \& Zabeau, M. (1995). AFLP: a new technique for DNA fingerprinting. Nucleic Acids Research, 23, 4407-4414.
Wang, H. Y., Lee, S. C. \& Yu, M. J. (1997). Genetic evidence to clarify the systematic status of the genera Zacco and Candidia (Cypriniformes: Cyprinidae). Zoological Studies, 36, 170-177.

Wang, H. Y., Tsai, M. P., Yu, M. J. \& Lee, S. C. (1999). Influence of glaciation on divergence patterns of the endemic minnow, Zacco pachycephalus, in Taiwan. Molecular Ecology, 8, 1879-1888.

Wassersug, R. D. (1976). A procedure for differential staining of cartilage and bone in whole formalin-fixed vertebrates. Stain Technology, 51, 131-134.

Winfield, I. J. \& Nelson, J. S. (1991). Cyprinid Fishes: Systematics, Biology and Exploitation. New York: Chapman \& Hall Press. 